\title{
Reading Challenges Confronted by Learners in Inclusive Primary Schools
}

Lloyd Daniel N. Tlale, Department of Psychology of Education, University of South Africa, https://orcid.org/ 0000-0002-4658-0421

\begin{abstract}
There is a national outcry about learners who read below the required levels and that poor matriculation results are, in part, due to the low levels of learners' reading skills. The main aim of this study is reading challenges experienced by learners in the primary schools. The researcher used a qualitative method for the study. The case study research design was adopted for the study. Three schools were sampled for the study. Data was collected through interviews, observations and document analysis. The findings indicated that learners experiencing reading difficulties often confuse letters and sounds, have difficulty in putting sounds in the correct order, struggles to read longer words, do not understand or remember easily, indulge with letter reversal and inversion and therefore, lack interest in the reading material. The study recommends that teachers and parents need to serve as reading models and instil the culture of reading.
\end{abstract}

Keywords: Effective reading skills; Extrinsic barriers; Inclusive primary schools; Literacy skills; Reading challenges.

Received: 15.11 .2020

Accepted: 19.12 .2020

Published: 04.01.2021

\section{INTRODUCTION}

The ability to read is not in-born like the ability to speak. A learner does not acquire an ability to read, simply by watching and listening while others read. Reading is a skill that must be deliberately learned. School learning depends largely on reading competence, thus early and sustained failure in reading can have devastating consequences in the lives of poor readers and their families and in the socio-economic life of the community (Hopkins, Clegg \& Stackhouse, 2018).

Lount, Purdy and Hand (2017), state that the most important element of high-quality education is literacy and that without the ability to read, learners are denied pertinent information about health, social, cultural and political issues as well as sources of pleasure and enrichment. Reading is part of nation building and it enables us to act creatively and critically in a world which is ever changing and competitive, it provides rapid and ready access to new information and knowledge that will help us in life-long learning (Department of Education, 2008). Snow, Woodward, Mathis and Powell (2016), declare that the ability to read is a critical component of school success and that a strong correlation exists between poor reading ability and school failure.

There is, however, a national concern that learners lack the necessary reading abilities to make a success of their academic years at school and at tertiary level institutions (Hugo, le Roux, Muller \& Nel, 2005). The reading research in South Africa indicates that in general, learners' reading skills are poorly developed and this applies from primary school through to tertiary level (Pretorius \& Machet, 2004). Locally, this problem is often raised in principals' meetings, in teacher forums, union meetings and in the media. Research reports indicate that many young learners attending South African schools have a reading problem (Hugo, 2010).

In 2001 and 2004 The Department of Education conducted two national systemic evaluations to establish literacy and numeracy levels in primary schools and these, showed low levels of reading ability across the country (Department of Education, 2008). The 2008 national systemic report that was based on the results of 1000 grade three classes, indicated that eight out of every ten learners obtained less than $50 \%$ for language skills and mathematics and that $35 \%$ of grade threes country-wide obtained between $0 \%$ and $34 \%$ for literacy which included reading. In the latest Progress in International Reading Literacy Study (PIRLS) done in 2006 where forty countries participated in the study, South Africa's score was the lowest of all the participating countries (Hugo, 2010).

Systemic evaluations conducted by the National Department of education, the Provincial Department of Education as well as the international bodies, reflect that learners in South African schools performed poorly 
when tested of their ability to read at age appropriate levels hence the National Department of Education has initiated several campaigns to help improve learners' reading levels. Research shows that in most developing countries, illiteracy is a severe problem. The inability of learners to develop effective reading skills is a cause for concern hence the need for inclusive education (Department of Education, 2008).

Major international conferences such as Jomtein (UNESCO, 1990), Salamanca (World conference on special needs education: UNESCO, 1994) and Dakar (World education forum, 2000), provided the momentum for many countries to develop policies to promote inclusion. For inclusion to become a reality in South Africa, transformations that are supported by the enhanced education system that is able to provide the necessary infrastructure, resources and support needed, has to occur to enable schools to change (Du Toit \& Forlin, 2009). Rodriguez and Dieker (2018), asserts that inclusive education is a product of education in the Western developed countries that have spread at the instigation of international organizations. It is a plan for educational development that is based on the concepts of human rights and peace. It stresses respect for individual differences (diversity), education for all in regular schools with the necessary provision of guidance and support for the learner's needs and it combats all forms of discrimination.

Inclusion means creating learning sites where all learners are welcomed and supported, and diversity is effectively responded to. Inclusive education is not only concerned with learners with disabilities, but all learners who may find learning difficult or inaccessible. Inclusion involves bringing support services to the learner rather than moving the learner to the services. It means that we need to change the way we have been looking at the learners and the system. Teachers are expected not only to focus on the intrinsic barriers of the learner but also the extrinsic or contextual barriers which may prevent the child from learning (Dawber, 2005; Landsberg, Kruger \& Nel, 2005), opine that inclusion is about developing inclusive community and education systems. Engelbrecht, Green, Naicker \& Engelbrecht, 2003), refers to inclusive schools as the ones that foster the personal, academic and professional development of all learners. They are free from harassment and discrimination and are about creating an inclusive learning environment which is about respecting learners and valuing them as partners in teaching and learning.

The motivation for undertaking the study relates to the researcher's personal experience as an teacher, the need to make a difference in the lives of learners experiencing reading challenges in the primary schools in inclusive schools in Pretoria, South Africa, and lastly to add value and to contribute positively in the development of the education systems in order to ensure that learners are able to read at the required level.

\section{LITERATURE REVIEW}

Johnson (2019), declares that given the pivotal role reading plays in and out of school and the cumulative longterm cost of literacy, intervention is critical especially at the primary schools. The primary schools' educational program is profound in its potential as an asset for promoting the success of the nation's children. It provides a measurable return on the public's investment (Pianta, Cox \& Snow, 2007).

To read for understanding, to express educated opinions on a subject, and to apply our reading ability and knowledge to new situations, are certainly long-range goals of any reading and literacy program. How teachers reach these goals and produce readers who have these abilities, have been debated through centuries by philosophers and scholars who recommend that 'just as there is no one type of child in the reading classroom, there is not one approach to the teaching of reading instead, instruction need to match the learner's academic needs (Reyes \& Hwang, 2019). Russell \& Santoro, 2007), maintains that carefully designed instruction is required, to help learners at risk of academic failure, to attain grade-level expectations.

\section{The levels of reading in South Africa}

In South Africa there are many students studying at tertiary level whose levels of literacy are not in line with the academic standards demanded by their studies. In a research project conducted by the students' service bureau of the University of the Orange Free State, the reading level of sixty first year students were tested. Not one of the students reading level was higher than grade eight and thirteen of them were only able to read at grade one and two levels. (Hugo, le Roux, Muller \& Nel, 2005)

In another study conducted by the Unit for the development of language abilities, it was found that the language ability of 2000 out of 6000 first year students was on the same level as or even lower than that of a grade seven learner (Hughes, Chitsabesan, Bryan, Borschmann, Swain, Lennox \& Shaw, 2017). Some students also had poorly developed reading and writing skills. It is thus clear that there are many students in South 
Africa who might have the potential to study successfully at tertiary level but lack the necessary literacy skills which also include reading, to guarantee academic success (Hugo, le Roux, Muller \& Nel, 2005).

In the year 2001 and 2004, the National department of Education conducted two national systemic evaluations to establish the literacy and numeracy levels in primary schools. The findings of the evaluations revealed that $54 \%$ of grade three learners are not on par regarding reading competency. The surveys showed low levels of reading ability across the country. The average score for reading and writing of 52000 grade three learners from 1400 mainly urban schools was 39\%. These statistics would be far worse in rural areas (Department of Education, 2008; Hugo, le Roux, Muller \& Nel, 2005).

De Witt, Lessing and Lenyai (2008), state that in response to the poor reading levels of learners, the National Department of Education has endeavoured running a number of campaigns to improve the current situation. Several campaigns were initiated by the different Ministers of Education such as: the Ithuteng "ready to learn campaign" and the Culture of Learning, Teaching and Services (COLTS), the South African Literacy Initiative (SANLI), Masifunde Sonke, the National Reading Strategy and the foundations for learning campaigns (Department of Education, 2008).

The researcher will focus on the following campaigns as they relate to the study, that is,

"The National Reading Strategy" launched in 2008 as a result of South Africa's participation in a number of United Nations' development campaigns which aim to increase the literacy level/rates by $50 \%$ by the year 2015. The main goal of the National Reading strategy is to improve the reading competence of learners, including those who experience barriers to learning and those learners who are at special schools (Department of Education, 2008).

In developing the "National Strategy for reading", South Africa is participating in a number of United Nations development campaigns which include the UNESCO Literary Decade 2003-2013, and the Education for All campaign which aim to increase literacy rates by $50 \%$ by the year 2015 . Underpinning these campaigns, are the Millennium Development Goals (MDGs) which has at its heart, literacy promotion (Department of Education, 2008). According to the Department of Education, South Africa will not participate in any regional or international studies assessing learner competency levels in literacy and numeracy in the GET band until the end of the literary decade (Department of Education, 2008).

The Foundations for learning campaign (FFL) launched in 2008, is a four-year campaign to create a national focus to improve the reading and numeracy levels of all the South African learners. The campaign propagates that learners and teachers should "drop everything and read" for thirty minutes on daily basis in schools, to improve learner performance in reading, writing and numeracy. Relevant tools and resources are provided to enhance effective teaching and learning (Department of Education, 2008).

The culture of learning and teaching campaign (COLTS) launched in 2009. The campaign is intended to ensure that quality teaching and learning is implemented in all schools (Johnson, 2003). This campaign is meant to improve the reading proficiency levels of all learners and to develop their reading skills.

The Learner Attainment Improvement Attainment Plan (LAIP) launched in 2010, is a plan that outlines the provincial intention of providing quality curriculum delivery to all learners. One of its objectives is to improve reading abilities of learners in the primary schools (Department of Education 2011).

\section{International perspectives on reading difficulties}

Hugo, Le Roux, Muller and Nel (2005), declare that 40\% percent of the children in the USA (United States of America) experienced significant problems in becoming competent readers and that more than $40 \%$ percent of fourth and eighth graders failed to read at the level considered basic to perform grade- level school work (Hugo, Le Roux, Muller \& Nel, 2005). In 2002, the United States Department of Education reported that of the 2, 887217 school aged children receiving services for learning disabilities, the majority were identified as having a learning disability because of the developmental delays in reading (Martin \& Carvalho, 2008).

For years, the media have clamoured about the poor state of reading in American schools. On the International Educational Achievement study, done in the early 1990's, Americans' 9-year olds scored second in the world, surpassed by children from Finland. Fifteen-year olds tied for fifth place behind New Zealand, France, Sweden and Finland. But in 1996, 40\% of United States' fourth graders could not read on this basic level even in narrative text under the supervision of teachers (Kim, Bryant, Bryant \& Park, 2017). For black learners and Hispanic learners' results were even worse: $69 \%$ of black fourth graders and $64 \%$ of Hispannic fourth graders could not read at basic levels. At higher grades, $30 \%$ of the eighth graders and $25 \%$ of the twelfth graders on the 1996 NAEP survey lacked the basic reading ability. (Temple, Ogle, Crawford \& Freppon, 2005) 
Dutch students achieved high average performance level in an International comparative study of reading comprehension conducted in 2001 but, this high average performance levels hide some undesirable significant differences. About seven percent of Dutch fifteen-year olds cannot read well enough to function independently in wider society (Cook, Kilgus \& Burns, 2018). The European average for fifteen-year olds who cannot read sufficiently well to function independently in wider society is just over seventeen percent (Houtveen \& Van de Grief, 2003). Research indicates that reading difficulties experienced by learners are issues of international concerns that warrant undivided attention and focus.

\section{Factors influencing reading}

South Africans studies of academic achievement consistently find strong and positive correlation between socio-economic background and academic performance. Children from poor families tend to perform poorly in tests of reading and mathematics and that twenty-five percent of achievement is explainable in terms of the social background of the learners (Fleisch, 2008).

The Department of Education (2008), cites the following as socio-economic factors exacerbating reading difficulties in South African schools i.e. family conditions, poverty, instability, resources, teacher competence.

Family poverty can potentially impact student's academic performance. Students whose families live in poverty often come to school without their basic needs being met. Poverty is harmful to one's mental and physical wellbeing. The limitations poverty places on families are likely to impact students' performances in school. Although the students' level of poverty is not automatically determining success or failure at school, this proportionate number of students from low income families are less successful in school and eventually drop out (Department of Education, 2008).

Most families experience changes from time to time but some changes in families are hazardous to students' emotional and physical wellbeing and to their progress in school. Most common jolts to family stability are divorce, family mobility (lack of permanent place to live in) drug abuses, health, violence, Parents who has limited access to education, Parents who are at work most of the time and illiteracy (Vaughn, Bos and Schumm, 2000; Department of Education, 2008).

Pretorius \& Mampuru (2007) and Makoe (2007), in their studies attest their findings that South African schools are not well resourced with libraries and most of them are without books and as such learners have no opportunity to read and spent most of their time in print poor environment. Learners from these environments are unable acquire reading levels similar or on par with their peers and often feel inferior or do not perform to the expected level.

The education language policy stipulates that learners should start learning at school in their home language until grade three. In most schools, the language of instruction for all subjects, changes in grade four from African languages to English as a medium of instruction. However, despite the language-in-education policy of 1997, it is still the case that most learners in South Africa do not learn in their mother tongue. Most schools have inadequate language policies which do not address the learning needs of the learners.

They do not ensure the right of learners to learn in their mother tongue especially primary schools' learners. Learners who are unable to speak properly also experience difficulties in reading (Department of Education, 2008). This affect learner's reading efficiency.

Learner's level of language development is an important factor in their ability to read. Language skills are directly related to the achievement in and adjustment at school and they are divided into the following categories: vocabulary, language comprehension, correct language usage, correct sentence construction, reading and spelling. The language education policy stipulates that learners should start learning at school in their home language until grade three. In most schools, the language of instruction changes from African languages to English which means that more than $80 \%$ of South Africans learn in a language different from their home language (Howie, Venter \& van Staden, 2008).

Educational factors such as exposure to print, opportunity to engage in literacy activities, quality of early reading instruction and opportunity for appropriate instruction is identified as one of the factors that influence reading (Vaughn, Bos \& Schum, 2003).

The Revised National Curriculum envisions teachers who are qualified, dedicated, competent and caring, who would be able to fulfil various roles outlined. Regrettably, most teachers do not meet the requirement and this impact teaching and learning negatively. The NCS requires teachers to develop their own learning programmes according to the learner needs which leads to frustration to most teachers who do not know what is expected or required of them. Learners cannot acquire reading proficiency when teachers 
themselves do not know how and when to teach reading. There has been a misunderstanding about the role of the teacher in teaching reading in curriculum 2005 and the National curriculum Statement. The employment of under-qualified teachers had an influence on quality of teaching and learning (Department of Education, 2008)

South African schools are not well resourced with libraries and most of them are without books. Pretorius and Mampuru (2007), claim that only 27\% of schools have libraries in South Africa. The national Department of Education also noted that some learners are enrolled in school that are ill equipped, overcrowded, and in desperate need of renovations. Crowded and dilapidated classrooms hinder the implementation of the National Curriculum Statement (NCS). High learner-teacher ratios combined with poor physical conditions and inadequate facilities for teaching and learning, schools with no libraries or print rich environments will always make reading a difficult task (Department of Education, 2008).

Many teachers in South Africa have an underdeveloped understanding of teaching literacy, reading and writing and do not know how to teach reading. Too often teachers know and use only one method of teaching reading which may not suite the learning style of all learners. Reading difficulties will always be experienced if diversity is not observed and learners are not supported. This further includes the negative attitude of teachers towards inclusive education, parental recognition and involvement, resistance to curriculum innovation and moral degeneration (Department of Education, 2008).

Textual factors such as the reading levels, type of text, vocabulary use and control, clarity of writing style and the complexity of writing affect the learner's reading competence (Vaughn, Bos \& Schumm, 2003). Ghanaguru, Liang \& Kit (2006), refer to the following as emotional factors that constitutes barriers to effective reading namely, lack of prior knowledge, lack of confidence, motivation and bad reading habits and unstable environment. The discussion on the theoretical framework will be discussed.

\section{Theoretical Framework}

For many decades educational psychologists have grappled with the problem of how learning occurs and to date, this has proved to be much more complex and intriguing as reflected by theorists in various theories of learning (Jansen, 2009). The researcher will provide a brief discussion of learning theories related to the reading instruction as the theories will provide the underpinnings of reading instructions.

\section{Constructivism}

Mergel (2011), surmises that constructivism is based on the premise that we all construct our own perspective of the world through individual experiences and schema and it helps the learner to be able to solve problems in ambiguous situations. A major influence on the rise of constructivism has been theories and research in human development of Vygotsky (Schunk, 2008).

Vygotsky's theory forms the cornerstone of constructivist movement. Vygotsky placed emphasis on the role of social mediation of knowledge construction that is central to many forms of constructivism therefore, his theory lies in dialectical constructivism's perspective which holds the idea that knowledge derives from interactions between persons and their environments (Nation, 2017). Constructions are not invariably bound to the external world or wholly the workings of the mind. Rather, knowledge reflects the outcomes of the mental contradictions that results with one's interaction with the environment $\left(\mathrm{O}^{\prime} \mathrm{Connor}\right.$, 2018). This dialectical view is useful for designing interventions to challenge learner's thinking. Social constructivist view, stresses that social group learning and peer collaboration are useful and that learning, and development cannot be dissociated from their context (Schunk, 2008).

According to constructivists, learning should be situated in realistic settings; testing should be integrated with the task and, not a separate activity and learners should be actively involved. Lastly, teachers should not teach in the sense of delivering instructions to learners but rather, they should facilitate learning (Reed, Cummings, Schaper, Lynn \& Biancarosa, 2019). Constructivism underlies the emphasis on the integrated curriculum in which students study a topic from multiple perspectives and that teachers should not teach in a traditional way but should rather structure situation such that learners become actively involved with content through manipulation of content and social interactions (Rosa, Tapia \& Perea, 2017).

Constructivist assumption is that teachers should not teach in the traditional way rather, they should structure learning such that learners are actively involved, provide support and guidance rather than lecturing, place emphasis on reflective teaching, stress that social group learning and peer collaboration are useful because as learners model for and observe each other, they teach not only teach skills but also experience higher self-efficacy for learning (Schunk, 2008). 
Constructivist assume that knowledge is first constructed in a social context and is then appropriated by own individual. Constructivists view learning as an active process while learners discover concepts. According to the constructivists individual learners make meanings through the interaction with each other and with the environment they live in similarly, OBE also encourages group work and interaction amongst learners and the learning content is context based (Stevens, Walker \& Vaughn, 2017).

\section{METHODOLOGY}

The study used the qualitative approach to understand reading challenges confronted by learners in inclusive primary schools. McMillan and Schumacher (2014), as well as Creswell and Poth (2018), indicate that qualitative research is an investigation in which researchers' collects data by interacting with selected persons in their own environment. It describes and analyzes people's individual and collective social actions, beliefs and the meaning that people assign to them.

McMillan \& Schumacher (2014), further state that it is based more on constructionism, which assumes multiple realities are socially constructed through individual and collective perceptions or views of the same situation and is more concerned with understanding the social phenomenon from the participant's perspective. The data collection strategies that were used included interviews, observations and document analysis.

\section{Research design}

Creswell and Poth (2018), describe research designs as specific procedures involved in the research process whereas De Vos, Strydom, Fouche and Delport (2011), refers to the research design as those decisions a researcher makes in planning a study.

The researcher will employ a case study design for the study. McMillan \& Schumacher (2014), concur with Creswell and Poth's (2018: p. 45) definition that state "A case study is an in-depth exploration of a bounded system based on extensive data collection". Case studies can be used to illustrate an issue and a focus may be on one entity (within site study) or several entities (multi-site study). The researcher will focus on several schools (i.e. multisites) therefore the researcher will use multiple or collective case study design for the study.

\section{Sampling}

In qualitative studies, non-probability sampling methods are utilized, and purposive sampling techniques are often used. In purposive sampling, a case is chosen because it illustrates a process that is of interest for a specific study (De Vos et al., 2011). The researcher will select participants from three primary schools within an inclusive setting in Pretoria, South Africa. Schools will be selected accordingly according to their accessibility and relevancy e.g. schools with remedial classes will be preferred as they will relate to the research problem. Only teachers and learners in the primary schools will be selected for the study

\section{Ethical Considerations}

While the researcher carries out the research study, s/he will be guided by ethics in research. Ethics is 'that branch of philosophy relating to human conduct with respect to the rightness or wrongness of certain actions, and to the badness or goodness of the motives and ends of such actions' (Ramirez, 2019: p. 36). Daniel (2016), defines ethics as professional rules and codes of conduct that guide the researcher in her dealings with participants like orphaned children and teachers. In essence, ethics in research ensure that the researcher shows acceptable conduct in order to protect the participants, self and the profession. It is vital to the success and failure of an educational research study (Garreta-Domingo, Sloep \& Herna'ndez-Leo, 2018). The researcher will observe ethical principles such as informed consent, privacy, confidentially and anonymity and nonmaleficence.

Prior to the study, informed consent will be sought from the participants as required by research ethics. A clearance letter to carry out the study will be sought from UNISA Research Ethics Committee of the faculty of education. The researcher will seek the permission to conduct the study in schools from the (Department of Education, 2008). Permission to carry out the study in schools will be sought from the Heads of the secondary schools. Informed consent letters will be sent to parents or guardians of the orphaned children requesting their permission to allow their children to participate in the study. The letters will spell out the nature of the study and the activities that the children will be engaged in. Orphaned children who will partake in the study will be requested to complete the assent forms and teachers to fill in the consent forms. Participants will be made aware of both the pros and cons of participation. The benefits and the risks that could arise if they 
participate in the study will be clearly outlined (Ramirez, 2019). This means the researcher will unveil the purpose of the research and the research procedure to the participants (Rodriguez-Morales \& Martinez de la Pena, 2018). Participants will be informed that they are free to withdraw from participating at any time if they want to. This then means that participation in the research will be voluntary. All signed informed consent copies will be kept in a safe place by the researcher in case of complaints upon release of the report (Jones, Brown \& Holloway, 2013).

\section{RESULTS AND DISCUSSION}

De Vos et.al (2003), state that education in South Africa has always been influenced by the educational systems in other countries and has always served a political purpose with opposing points of views and that at no period of time in its history was education the spontaneous expression of the ethos of the South African people

Teachers from School A (a1, a2) School B (b1, b2 \& b3) and School C (c1 \& c3) participant that they are no longer sure of what they do because instead of teaching learners teachers concentrate more on paperwork. "Teachers concentrate more on administrative work rather than actually teaching learners".

The school manager from school B remarked that learner's reading problems are in part related to curriculum changes which are often not well understood by teachers.

Who are expected implement and some principals who are also expected to lead the process? Teacher (b2) from school B alleges that learner's reading difficulties are increased by the curriculum which does not say much about how and when must reading be taught and what to teach, there are no graded readers in schools. So, every individual teacher teaches reading whenever he/she feels like.

\section{Lack of resources}

Fleisch (2008), states that South African studies of academic achievement find strong and positive correlation between socio-economic background and academic performance and that a full $25 \%$ of achievement is explainable in terms of the social background of pupils and that studies indicate that there is a strong relationship between poverty and performance and that poverty is linked to underperformance.

All participants from school $A, B \& C$ alleges that lack of resources especially in rural areas exacerbate reading difficulties especially in the foundation phase. Most teachers who are qualified with specific expertise often go for greener pastures as a result schools are to settle for under qualified, underperforming and aged teachers. The school manager from school $A$, remarked that lack of dedication from teachers, lack of interest from learners and parents exacerbate reading difficulties in schools.

The school manager from school $C$ remarked that learners do not read at the required level because their teachers also do not read, therefore the culture of reading is not instilled among learners.

\section{Discipline}

According the South African Schools Acts (SASA) (1997), state clearly that corporal punishment may no longer be used in schools as well as section 12 of the constitution which state that everyone has the right not to be treated or punished in a cruel, inhumane or degrading way as a result schools are governed by lawlessness, bullying. Principals from the three primary schools remarked that learners in their schools are uncontrollable; they do as they wish and are aware that law is in their favour so there is little that they (as principals) can do to change the situation. "Teachers send offenders to the office, parents do not respond when called it is just a mess, the situation is unbearable and calls for our early retirement Everybody and everyone does as he wishes at this time and era" (Principal of school B).

In school C (c1, c2 \& c3) responded that teachers in the foundation phase classes are faced with overcrowded learners in their classrooms and are unable to support learners individually to ensure effective teaching and learning "Teachers are redeployed to other institutions even if schools become dysfunctional after their departure."

\section{Impairments}

Teachers revealed that learners come to school with various impairments which are sometimes discovered at later stages. In most instances, learners experience reading difficulties as a result of their impairments.

"Children of this day and era are born with major physical defects and need to be handled with care."(Teacher of school C) 


\section{Constant failure}

Darrel (2005), opines that early and sustained failure in reading have devastating consequences in the lives of low readers, their families and in the socio-economic life of the community. The national protocol for assessment Grade R-12, states that promotion requirements from grade to grade through the foundation phase should be within the appropriate age cohort, and the no learner retention in the phase for more than four years should be the accepted norm. That, according to teachers' responses, leads to conditional promotions which negatively affects learner's performances and causes constant failures which results into bullies and teenage suicides and others.

\section{Inferiority complex}

Different teachers from the three different schools unanimously named the following manifestations of learners with reading difficulties. They stated that learners are withdrawn in the classroom situation, they are instilled with fear of not participating in the reading activities as they will be laughed at or scorned by other learners, they are afraid to make mistakes or to attempt reading anything. They often indulge in rote learning or lip-reads or mimic as others are reading.

\section{School dropouts}

In the report by NCES (National Committee on Education Support) and the NCSNET (National Commision on Special Needs in Education and Training) White Paper 6 (2001: p. 5), one their findings was that "the curriculum and the education system as a whole has generally failed to respond to the diverse needs of the learner population, resulting in massive numbers of drop-outs". Interviews revealed that even if learners are identified and supported at the foundation phase, they are neglected as they progress to the upper levels and as a result, they regress, bunk classes and ultimately become dropouts.

\section{Support required by teachers}

Interviewees from school $A$ and $C$ responded positively and commended the Department for their innovation whereas a teacher from School B responded negatively indicating that she is stuck with the severely impaired learners with no help or guidance from the subject specialists or superiors.

The specialist remarked that the area office is understaffed with no transportation for ensuring that schools are guided and supported on inclusive education therefor support to schools is minimal.

\section{Strategies employed for teaching reading}

All interviewees (teachers) from the three primary schools prefer using the mixed methods strategy for teaching reading as they allege that there is no "one good prescribed method" for teaching reading.

\section{Learner support measures in schools}

The participants from all the different schools identified the following as support measures in school for teaching reading namely: the strategic plan on teaching reading (e.g. Molteno programme), the intervention programmes on reading, the Individual Educational Plan (IEP) for learners experiencing reading difficulties and the enrichment programme for learners who can read.

The study indicates that education is a societal issue and that there is positive correlation of learner's socio-economic background and the learner's reading proficiency for an example, learners from poor home backgrounds and unstable environments' reading difficulties are more than those of learners from good stable home backgrounds. Ghanaguru, Liang, \& Kit (2006), identify, lack of motivation, unstable home environments, lack of motivation and prior knowledge as factors that constitute barriers to effective reading.

It was observed, in this study, that learners experiencing reading difficulties often display the following similar and common difficulties for example, they often confuse letters and sounds, have difficulty in putting sounds in the correct order, struggles to read longer words, do not understand or remember easily, indulge with letter reversal and inversion and lack interest in the reading material.

The study contributes immensely to improve the learner's reading levels. It is imperative that foundation phase educators take the lead in ensuring that learner's reading levels are drastically improved and augmented. Research indicates that no method can be singled out as the best method for teaching reading therefore, educators as experts in their own making need to alternate various methods for teaching reading. 


\section{CONCLUSION AND RECOMMENDATIONS}

This paper investigated reading challenges confronted by learners in inclusive primary schools. From the study, it can be concluded that the lack of dedication amongst teachers to teach reading, lack of experience and expertise and skill to teach reading, that poverty and school conditions contribute immensely to reading difficulties. Parental involvement is still lacking especially in rural schools, and inclusion is not well cascaded to lower levels of the schools and that there is no specified curriculum in pre-schools. The teachers need intensive training to become experts and specialists to improve reading skills and to keep pace with innovation in education. In addition, the classes are overcrowded and there is continuous interruption that inhibits quality teaching and learning and appropriate support.

The study recommends that regular workshops and meetings be held regularly at school level to educate parents about the importance of their contributions towards their children's education and discipline as charity begins at home. In addition, it is also recommended that the department of education employ strategies and measures of ensuring discipline in schools as no learning will occur in an ill-disciplined environment.

All schools need to be well developed and resourced irrespective of them being in the rural areas or not, to enable all learners to be exposed to various reading material to widen their horizon and to be able to compete with their peers locally and globally without feeling inferior.

A limitation of this study is that the study is limited to three primary schools in the village. Only primary school teachers and learners are selected for the study. The schools are selected on the basis that learners who experience learning difficulties are transferred to these schools for proper support and guidance. The schools are located in the semi-rural area whilst one is in the deep rural area. The schools are far apart from one another but the distance in between is bearable. Most of the people in the community around these schools are unskilled, unemployed and are the are the poorest of the poor.

\section{REFERENCES}

Creswell, J. W., \& Poth, C. N. (2018). Qualitative inquiry and research design (4th ed.). Thousand Oaks, CA: Sage Publications.

Cook, C. R., Kilgus, S. P., \& Burns, M. K. (2018). Advancing the science and practice of precision education to enhance student outcomes. Journal of School Psychology, 66, 4-10. https://doi.org/10.1016/j.jsp.2017.11.004.

Daniel, E. (2016). The usefulness of Qualitative and Quantitative Approaches and Methods in Researching Problem Solving Ability in Science Education Curriculum. Journal of Education and Practice. Vol.7, No.15, 4556

Darrel, M. (2005). The Howard Street Tutoring Manual: Teaching at-risk readers in the primary grades. London: Guilford Press.

Dawber, A. (2005) Inclusive education: Institutional-level Support Teams Manual. North Western Province. Department of Education (2011). National Reading Strategy: Department of Education. Pretoria:

Department of Education. Pretoria: South Africa.

Department of Education (2008). Government Gazette South Africa. Vol. 513 no: 30880 Foundations of Learning Campaign. Pretoria: South Africa.

Department of Education (2001), Education White Paper 6 Special Needs Education: Building an Inclusive Education Training System. Pretoria

De Vos, A. S., Strydom, H., Fouche, C. B. \& Delport, C. S. L. (2011). Research at grass roots: For the social sciences and human services professions. (4th Ed.). Pretoria: Van Schaik.

De Witt. M.W, Lessing A.C and Lenyai, E. M. (2008). An investigation into the state of early literacy of preschool learners. Journal for language teaching 42/1-24.

Engelbrecht, P. Green, I. Naicker, S \& Engelbrecht, L. (2003). Inclusive education in action in South Africa. Pretoria: Van Schaik.

Fleisch, B. (2008). Primary education in crisis: Why South African schoolchildren underachieve in reading and mathematics. Cape Town, South Africa: Juta.

Garreta-Domingo, M., Sloep, P. B., \& Herna'ndez-Leo, D. (2018). Human-centred design to empower

"teachers as designers". British Journal of Educational Technology, 49 (6), 1113-1130. https://doi.org/10.1111/bjet.12682 
Ghanaguru, S, Liang, N. H. \& Kit, N. L. (2010). An initial study of reading problems and strategies: a

teacher's perspective. IPBA Journal, 3(1): 17-38. [online] Available at: http://apps.emoe.gov.my/ipba/rdipba/cd1/article56.pdf. [15/09/2010].

Houtveen, A. A. M, \& Van de Grift, W. J. C. M. (2007). Reading instruction for struggling learners. Journal of education for students placed at risk, 12 (4): 405-424.

Hopkins, T., Clegg, J., \& Stackhouse, J. (2018). Examining the association between language, expository discourse and offending behaviour: An investigation of direction, strength and independence.

International Journal of Language \& Communication Disorders, 53 (1), 113-129. https://doi.org/10.1111/1460-6984.12330

Howie, S. J, Venter, E. \& Van Staden, S. (2008). The effect of multilingual policies on performance and

progression in reading literacy in South African primary schools. In: S. J. Howie \& T. Plomp, eds. Reading achievement: international perspectives from IEA's progress in international reading literacy studies (PIRLS). Education Research and Evaluation, 14(6): 551-560.

Hughes, N., Chitsabesan, P., Bryan, K., Borschmann, R., Swain, N., Lennox, C., \& Shaw, J. (2017). Language

impairment and comorbid vulnerabilities among young people in custody. Journal of Child Psychology and Psychiatry, 58, 1106-1113. https://doi.org/10.1111/jcpp.12791

Hugo, A.J. (2010). Foundation phase teachers: The "battle" to teach reading. Journal for language teaching 44 (2), 23-36.

Hugo, A. J. Le Roux, S. G., Muller, H. \& Nel, N.M. (2005). Phonological awareness and the minimising of reading problems: a South African perspective. Journal for language teaching, 39 (2): 210-225.

Jansen, J.D. (2009). On the clash of martyrological memories. Perspectives in Education 27(2): 147-157. Johnson, A. (2019). The effects of English learner classification on high school graduation and college attendance. AERA Open, 5 (2), 1-23. doi:10 .1177/2332858419850801

Jones, I, Brown, L. \& Holloway, I. (2013). Qualitative Research in Sport and Physical Activity. London: Sage Publications Ltd.

Kim, K. K., Bryant, D. P., Bryant, B. R., \& Park, Y. (2017). A synthesis of interventions for improving oral reading fluency of elementary students with learning disabilities. Preventing School Failure: Alternative Education for Children and Youth, 61, 116-125. https://doi.org/10.1080/1045988X.2016.1212321. Landsberg, E. Kruger, D. \& Nel, N. eds. (2005). Addressing barriers to learning: a South African perspective. Pretoria: Van Schaik.

Lount, S. A., Purdy, S. C., \& Hand, L. (2017). Hearing, auditory processing, and language skills of male youth offenders and remandees in youth justice residences in New Zealand. Journal of Speech, Language, and Hearing Research, 60 (1), 121-135. https://doi.org/10.1044/2016_JSLHR-L-15-0131

Makoe, P. (2007). Language discourses and identity construction in a multi-lingual South African primary school. English academy review: Southern African Journal of English Studies, 24 (2) 55-70. [online] $<$ http://www.tandfonline.com/loi/racr20>.

Martin, M. \& Carvalho, K. (2008). (January/February) Reading and learning-disabled children: understanding the problem. The Clearing House: Heldref publications.

McMillan, J. H., \& Schumacher, S. (2014). Research in education: Evidence-based inquiry. Harlow: Pearson Higher Ed.

Mergel, B. (2011). Instructional design and learning theory [online] available at:

http://www.usask.ca/education/coursework/802papers/merge/brenda.html. [08.08.2011].

Nation, K. (2017). Nurturing a lexical legacy: Reading experience is critical for the development of word reading skill. Science of Learning, 2, 1-4. https://doi.org/ 10.1038/s41539-017-0004-7.

O'Connor, R. E. (2018). Reading fluency and students with reading disabilities: How fast is fast enough to promote reading comprehension? Journal of Learning Disabilities, 51, 124-136. https://doi.org/10.1177/0022219417691835.

Pianta, R.C, M. Cox \& K. Snow. (2007). School readiness and the transition to Kindergarten in the era of accountability. Baltimore: Brookes Publishing.

Pretorius, E.J. \& Mampuru D.M. (2007). Playing football without a ball: language, reading and academic performance in a high-poverty school. Journal of research in reading, 30 (1): 38-58.

Pretorius, EJ. \& MP Machet. (2004). The socio-educational context of literacy accomplishment in

disadvantaged schools: Lessons for reading in the early primary school years. Journal for Language Teaching 38 (1): 45-62.

Ramirez, E. J. (2019). Ecological and ethical issues in virtual reality research: A call for increased scrutiny. 
Philosophical Psychology, 32 (2), 211-233. https://doi.org/10.1080/ 09515089.2018.1532073

Reed, D. K., Cummings, K. D., Schaper, A., Lynn, D., \& Biancarosa, G. (2019). Accuracy and reliability in identifying miscues during oral reading. Reading and Writing: An Interdisciplinary Journal, 32, 1009-1035. https://doi.org/10.1007/s11145-018-9899-5.

Reyes, M., \& Hwang, N. (2019). Middle school language classification effects on high school achievement and behavioral outcomes. Educational Policy. Advance online publication. doi:10.1177 /0895904818823747

Rodriguez-Morales, L., \& Martinez de la Pena, A. (2018). Design for all as a research and $\sim$ education strategy. Strategic Design Research Journal, 11(3), 241-246. https://doi.org/ 10.4013/sdrj.2018.113.08

Rodriguez, J. A., \& Dieker, L. A. (2018). Emerging Inclusive Education in the United Nations Relief and Works Agency for Palestine Refugees in the Near East: A Review of the Literature. Journal of International Special Needs Education, 21 (1), 32- 42. doi: 10.9782/15-00018R2

Rosa, E., Tapia, J. L., \& Perea, M. (2017). Contextual diversity facilitates learning new words in the classroom. PLoS One, 12. https://doi.org/10.1371/journal.pone. 0179004.

Russell, G. \& L. Santoro. (2006). "Advances in research on teaching students who experience difficulties in learning:

grappling with the issue of access to the general curriculum 1." The SAGE Handbook of Special Education. SAGE Publications (http://www.sage-ereference.com/ hdbk_specialedu/Article_n15.html).

Schunk, D.H. (2008). Learning theories: an educational perspective. 5th ed. Upper Saddle River, N.J.

Pearson.

South African Schools Act (1997). South Africa.

Snow, P. C., Woodward, M., Mathis, M., \& Powell, M. B. (2016). Language functioning, mental health and

alexithymia in incarcerated young offenders. International Journal of Speech-Language Pathology, 18, 20-31. https://doi.org/10.3109/17549507.2015.1081291

Stevens, E. A., Walker, M. A., \& Vaughn, S. (2017). The effects of reading fluency interventions on the reading fluency and reading comprehension performance of elementary students with learning disabilities: A synthesis of the research from 2001 to 2014. Journal of Learning Disabilities, 50, 576-590. https://doi.org/10.1177/0022219416638028.

Temple, O., Ogle, D., Crawford, A. \& Freppon, P. (2005). (2nd ed.) All Children Read: Teaching for literacy in today's diverse classrooms. New York: Pearson.

UNESCO. (1990). Rules for the Protection of Children in conflict with the laws Deprived of their Liberty. 'The

Havana Rules', Office of the High Commissioner for Human Rights. Adopted by General Assembly Resolution $45 / 113,14$.

UNESCO. (1994). Final Report: World conference on special needs education: Access and quality. Paris: UNESCO.

Vaughn, S. Bos, C.S. \& Schumm, J.S. (2003). (2nd ed.) Teaching exceptional, diverse, and at-risk students in the general education classroom. Boston: Allyn\& Bacon.

World Education Forum Dakar (2000). Dakar Framework for Action, Senegal, 26-28 April 2000. 